\title{
Effects of Physical Therapy in Older Women with Urinary Incontinence
}

\author{
Vjollca Ndreu
}

Faculty of Technical Medical Sciences, University of Medicine, Tirana, Albania

Enkelejda Sina

Faculty of Technical Medical Sciences, University of Medicine, Tirana, Albania

Enkelejda Shkurti

Faculty of Technical Medical Sciences, University of Medicine, Tirana, Albania

Diamant Shtiza

University Hospital Centre: "Mother Theresa”, Tirana, Albania

\section{Doi:10.5901/mjss.2015.v6n1s1p183}

\begin{abstract}
Introduction: One of the most frequent public health issues between older females is urinary incontinence (UI). Regardless of conventional cure as the initial alternative, the outcomes of physical therapy in older females with UI is imprecise. Objective This survey intended to analytically assess the confirmation about the consequences of physical therapy on urinary indicators in older females with Ul. Method The literature exploration for surveys estimating traditional cure for incontinency in elderly females was performed on PubMed/Medline, Lilacs, Scielo, ISI Web of Knowledge. We picked medical tests published in English after the year 2003. The procedural quality of the surveys was appraised applying the Pedro degree. The effects were investigated using a significant assessment technique. Results: Eight surveys were entirely reviewed exposing that pelvic floor muscle exercise was the cure choice in most surveys. Seven of the eight chosen surveys were categorized as having elevated methodological excellence. There was considerable enhancement in urinary indicators after healing in seven of the eight selected surveys. Conclusions: It was finalized that physical therapy healing appears to be useful to reduce urinary incontinence signs in older females. Nevertheless, the tiny number of surveys and the use of concomitant interventions limit the ending on this matter.
\end{abstract}

Keywords: Urinary incontinence; Remedy; Treatment result; Elderly health

\section{Introduction}

Along with the International Continence Society (ICS), urinary incontinence (UI) is classified as an uncontrolled leakage of urine(1). It is one of the main public health issues between females of all ages, with an enhance in occurrence with aging (2). It is predicted that $22 \%$ to $48 \%$ of females, of diverse ages and throughout the world, experience involuntary urine outflow, whereas $7 \%$ to $36 \%$ of females above 60 years of age describe daily urinary outflow(3). In Brazil, surveys indicate UI has occurred in $24.6 \%$ and $37 \%$ of post-menopausal females experience $(4,5)$. Moreover, the escape of urine effects in harsh significances for the quality of life of the females influenced, will generate common, emotional and psychological collisions (6).

Taking into account the high occurrence and the financial, social and emotional consequences of $\mathrm{UI}$ in elder females, it is essential to establish a successful cure for this disorder. The ICS suggests conventional treatment as the primary line of healing for incontinent females with a spotlight on rising strength and correcting stimulated patterns of the pelvic floor muscles(7). The initial method used for the intensification and improvement of pelvic floor muscle enrollment was the pelvic floor muscles training with no use of any mechanism, suggested by Kegel (8) in 1948.

At present, numerous methods are utilized in medical practice intending to recover pelvic floor muscle role; such as electrical stimulus and vaginal funnels (9).

Many investigators propose that, in elder females, there may be a diminution in the reliability of the pelvic floor because of a decline in the amount of female reproductive hormones and getting old, such as alterations in the rate of 
diverse sorts of collagen and the privileged atrophy of type II muscle fibers(10-12).

The incidence of these modifications increase suspicions related to the usefulness of traditional treatment for elder females with UI. Consequently, this survey intended at methodically reviewing the scientific facts on the outcomes of corporal remedy on urinary incontinence symptoms in elder women.

\section{Methods}

We scientifically assessed clinical examinations that tackled the diverse types of physical therapy accessible for the cure of UI in elder females. The literature investigation was carried out on March, 2013 on the ISI Web of Knowledge, Medline/Pubmed, Lilacs, Scielo databases. The exploration was accomplished separately by two unsighted investigators who compared the outcomes.

Casual medical tests that were made known in English were considered for insertion in this examination. The survey substance was evaluated by two assessors and chosen by means of the subsequent enclosure criteria: a) contributors with reported urinary outflow; b) trial created of elder females simply (aged over 60 years); c) analysis of the results of various physical therapy procedure; d) surveys available following the year 2000. Studies that had to do with surgical interventions were left out.

The articles were explored completely applying a prepared type with the next items: model, results assessed, intervention features and healing achievements (13). Procedural value of the chosen scientific tests was appraised using the(14) PEDRo degree composed of twelve subjects, ten of which are calculated to an ultimate score. Every principle is attained prior to its occurrence or lack. Articles not illustrated in the studies are categorized as "not registered" and are not kept count. The concluding benefit varies from 0 to 10 and are acquired during the amount of all affirmative answers. Every selected survey was directed in the PEDRo record and consequently, quality scores were removed from the catalog. Surveys with results equal to or greater than five were believed of elevated procedural value(15).

\section{Results}

Thirty five articles were discovered by means of the illustrated exploration approach. We left out repetitive studies, literature appraisals and those that did not accomplish the recommended insertion criteria. Fifteen studies were picked for complete content selection. Amid those selected, five estimated only one interference arm (16-19) and three had a trial of females initializing from 57 years of age $(20,21)$ and were consequently eliminated (Figure 1). Therefore, five studies were included in the significant assessment phase.

A substance examination of the chosen studies exposed the heterogeneity of the cure modality which was assessed in the surveys. In five of the studies, pelvic floor muscle training exercises were the cure of preference in one of the healed clusters (22-26).

Nevertheless, this cure was utilized in seclusion in only two studies $(22,26)$. In three of the chosen studies, the instigators used non-insidious transcutaneous electrical stimulus on the tibia nerve(25) and extracorporeal captivating incentive(27). An involvement of intravaginal electrical stimulation was utilized in remoteness in an additional survey (22).

Two studies comprised females with grumbels of outflow connected to stress or compulsion(22,24,27). Kim et al and Sherburn et al (26) estimated treatment results in females with merely tension UI, though Schreiner et al (25) had to do with females with only urge UI. The trial dimensions of the involved studies sorted from 3689 to 9116 . The common age differed from 66.528 to 78.3974 years. The age insertion principles was diverse among the integrated studies.

Alternatively, Spruijt et al.22, Kim et al (23), Aslan et al (24) and Sherburn et al (26) believed 65 as the lowest age. In every survey, the sample was compiled of population based females whereas Aslan et al (24) calculated women in long-standing institutional care.

Effect measures to assess incontinence signs consisted of the micturition diary (24-27), diverse types of pad trials $(22,24,26,27)$ and the occurrence of incidents of urinary outflow $(23)$. Additional results estimated were value of life applying the King's Health Questionnaire (KHQ)24,25, the International Consultation on Incontinence Questionnaire Short Form (ICQ-SF)26,27.

A considerable enhancement in incontinence signs after the projected cure was observed in three of the six studies chosen (22-26). A lasting record among 6 months (24) and 1 year (23) were collected in two surveys $(23,24,26)$. The consequences illustrated that the results were sustained above the long term. 


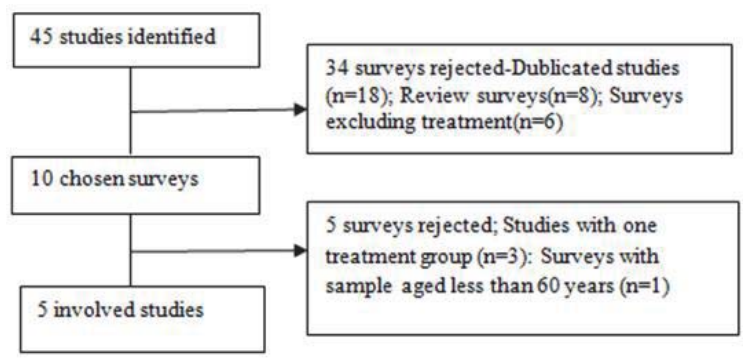

\section{Discussion}

The outcomes of this appraisal showed that despite of the UI category and the healing modality used, physical therapy involvements seem to endorse advantages in incontinent elder females, as an enhancement in urinary signs was examined in all surveys excluding one. It is recognized that urinary incontinence is one of the most significant and most frequent elderly issues(16).

The high occurrence of urinary incontinence among elder females may probably be clarified by the total of the results of post-menopausal hypo-estrogenism and maturing, that generate harmful outcomes in the woman urogenital area(10). The consequences of this review show that, regardless of the existence of basic age associated alterations, physical therapy can endorse an advance of incontinence signs in elder females.

Pelvic bottom muscle exercise was the pattern of choice for the mainstream of the surveys chosen. Many studies have estimated the efficiency of this sort of cure when matched up to the lack of cure for females with UI. In a current review, Dumoulin and Hay-Smith (28) appraised the outcomes of pelvic floor muscle exercise in females with stress UI matched up with those who stood untreated. The investigation of the seven surveys chosen demonstrated that incontinent females offered to be cured had 15 times more possibility of recovering from urinary signs than uncured females. Consequently, the amplification of the pelvic bottom muscles appears be efficient in the cure of urinary incontinence in females.

Nevertheless, for elder females, this treatment is slightly discovered. None of the surveys that tackled treatment in elder women has examined the results of pelvic bottom muscle exercise used in separation as matched up to an immobile control group.

Kim et al (23) and Aslan et al (24) evaluated a cluster treated with pelvic floor muscle exercise in combination with multidimensional exercises and bladder exercise to an stationary control bunch. This absence of surveys assessing pelvic base training in seclusion makes it hard to attain any terminations about this sort of cure, principally in the elderly people.

Schreiner et al (25) dealt with a lately suggested method for UI treatment. The instigators estimated the outcomes of conventional treatment related to transcutaneous electrical stimulus of the subsequent tibial nerve in the cure of elder females with urge UI, accomplishing superior effects to usual therapy in segregation. Amarenco et al (29) assessed the acute results of this procedure on uro-dynamic limits and discovered a diminution in hyperactivity and an enhancement in bladder aptitude after submission. The physiological outcomes of this cure may be clarified by the existence of posterior tibial nerve afferent filaments in the equal sacral protuberance of the bladder innervations. Thus, this incentive would generate a neuro-modulation in the area, reducing detrusor muscle afferent filaments, in that way decreasing the urge feeling(29).

Vandoninck et al (30) took care of females with UI signs for 12 weeks applying electrical stimulus of the posterior tibial nerve and discovering that $70 \%$ of the females had a diminution in urinary outflow incidents. The consequences with respect to this procedure are hopeful, however the existence of one survey with the submission of this treatment in the aged population constraints the endings.

An additional type of non-insidious cure is extracorporeal magnetic stimulus, founded on the theory that an alteration in the magnetic area can provoke an electron stream, that would permit the depolarization and tightening of the pelvic base muscles(31). This method would furthermore be well accepted by elder women as it is achieved without the requirement to remove the clothes excluding pain.

Wallis et al(27) checked the efficiency of this procedure in these individuals and did not discover any affirmative effects when contrasted to the cluster that got placebo therapy, illustrating an important influence of the placebo outcome on the consequences. Conversely, the sample dimension of the comprised study restricts results on this method and 
additional studies must be executed.

The long-standing record of corporal therapy outcomes is crucial in accomplishing results on the usefulness of the involvements. All of the chosen surveys that involved an extended follow-up assessed pelvic base muscle exercise. It is well recognized that it is essential to keep on the exercises so as to sustain the advantages of pelvic floor muscle exercise (32).

It was observed that only one study estimated the results of physical treatment for $\mathrm{UI}$ in institutionalized elder females. UI is extremely prevalent in institutionalized elder females, being believed one of the main reasons of institutionalization. Concomitant illnesses, practical incapability and vulnerability may persuade the power of the sphincter control and the flexibility to a toilette, that may rationalize the elevated occurrence of the disorder in this community $(34,35)$. The literature on this issue illustrate the psycho-social effects like sadness and segregation, and the physiological achievements, such as stress ulcers, that can arise as a consequence of this geriatric condition in this population residing females, but little is acknowledged of the effects of this situation in institutionalized elder women (36). Regardless of the complexities, the positive outcomes of the therapy of institutionalized elder women discovered by Aslan et al (24) persuade the inclusion of this sort of $\mathrm{UI}$ treatment in lasting care societies.

The mainstream of the surveys chosen had elevated methodological value, which aids the extrapolation of outcomes for medical practice. However, it should be taken into account that two surveys had at least cut-off achievement. This methodical estimation sought to collect recent, scientifically facts to increase medical practice and assist professionals in setting up their medical performance.

Nevertheless, a few number of clinical tests particularly executed on elder women emphasizes the requirement for original revision to estimate the consequences of diverse UI therapy patterns for elder women. To accomplish eventual conclusions these surveys must present an appropriate test dimension, the submission of isolated procedures as a category of leading the real effectiveness of every method, a lasting follow up as well as a tough procedural value.

\section{Conclusion}

Pelvic floor muscle exercise in separation or in conjunction with multidimensional trainings, and non-insidious transcutaneous electrical posterior tibial nerve stimulus appear to be efficient procedures in the diminution of urinary signs among elder females with UI.

It is distinguished that observance to post-cure trainings can be persuaded by hurdles, such as the diminution of the time and willingness in its implementation, the occurrence of traumatic conditions and the complexity in combining the training into each day actions (33). It is indispensable to illuminate the patients about the significance of long-term trainings post incursion with the intention of sustaining the consequences after the physical treatment has finished.

Conversely, a few number of surveys and the use of simultaneous treatment procedures controls

conclusions concerning the worth of detailed interventions and consequently, original studies require to be performed to supply a more ultimate conclusion on the outcomes of physical remedy in the cure of $\mathrm{UI}$ in elder women.

\section{References}

Abrams P, Andersson KE, Birder L, Brubaker L, Cardozo L, Chapple C, et al. Fourth International Consultation on Incontinence Recommendations of the International Scientific Committee: evaluation and treatment of urinary incontinence, pelvic organ prolapsed, and fecal incontinence. Neurourol Urodyn. 2010;29(1):213-40.

Temml C, Haidinger G, Schmidbauer J, Schatzl G, Madersbacher S. Urinary incontinence in both sexes: prevalence rates and impact on quality of life and sexual life. Neurourol Urodyn. 2000;19(3):259-71.

Buckley BS, Lapitan MCM; Epidemiology Committee of the Fourth International Consultation on Incontinence, Paris, 2008. Prevalence of urinary incontinence in men, women, and children - current evidence: findings of the Fourth International Consultation on Incontinence. Urology. 2010;76(2):265-70.

Tamanini JTN, Lebrão ML, Duarte YAO, Santos JLF, Laurenti R. Analysis of the prevalence of and factors associated with urinary incontinence among elderly people in the Municipality of São Paulo, Brazil: SABE Study (Health, Wellbeing and Aging). Cad Saúde Pública. 2009;25(8):1756-62.

Guarisi T, Pinto Neto AM, Osis MJ, Pedro AO, Paiva LHC, Faúndes A. Incontinência urinária entre mulheres climatéricas brasileiras: inquérito domiciliar. Rev Saúde Pública. 2001;35(5):428-35.

Dedicação AC, Haddad M, Saldanha MES, Driusso P. Comparison of quality of life for different types of female urinary incontinence. Rev Bras Fisioter. 2009;13(2):116-22.

Hay-Smith J, Bø K, Berghmans LC, Hendriks HJ, de Bie RS, van Waalwijk van Doorn ES. WITHDRAWN: Pelvic floor muscle training for urinary incontinence in women. Cochrane Database Syst Rev. 2007;(1):CD001407.

Kegel AH. Progressive resistance exercise in the functional restoration of the perineal muscles. Am J Obstet Gynecol. 1948;56(2):238- 
48.

Neumann PB, Grimmer KA, Deenadayalan Y. Pelvic floor muscle training and adjunctive therapies for the treatment of stress urinary incontinence in women: a systematic review. BMC Womens Health. 2006;6:11.

Chen Y, Chen GD, Hu SW, Lin TL, Lin LY. Is the occurrence of storage and voiding dysfunction affected by menopausal transition or associated with the normal aging process? Menopause. 2003;10(3):203-8.

Gopal M, Sammel MD, Arya LA, Freeman EW, Lin H, Gracia C. Association of change in estradiol to lower urinary tract symptoms during the menopausal transition. Obstet Gynecol. 2008;112(5):1045-52.

Rizk DE, Fahim MA. Ageing of the female pelvic floor: towards treatment 'a la carte' of the 'geripause'. Int Urogynecol J Pelvic Floor Dysfunct. 2008;19(4):455-8.

Ricci NA, Dias CNK, Driusso P. The use of electrothermal and phototherapeutic methods for the treatment of fibromyalgia syndrome: a systematic review. Rev Bras Fisioter. 2010;14(1):1-9.

Maher CG, Sherrington C, Herbert RD, Moseley AM, Elkins M. Reliability of the PEDro scale for rating quality of randomized controlled trials. Phys Ther. 2003;83(8):713-21.

Moseley AM, Herbert RD, Sherrington C, Maher CG. Evidence for physiotherapy practice: a survey of the Physiotherapy Evidence Database (PEDro). Aust J Physiother. 2002;48(1):43-9.

Padrós J, Peris T, Salvà A, Denkinger MD, Coll-Planas L. Evaluation of a urinary incontinence unit for community-dwelling older adults in Barcelona: implementation and improvement of the perceived impact on daily life, frequency and severity of urinary incontinence. Z Gerontol Geriatr. 2008;41(4):291-7.

Bakar Y, Cinar Özdemir O, Özengin N, Duran B. The use of extracorporeal magnetic innervation for the treatment of stress urinary incontinence in older women: a pilot study. Arch Gynecol Obstet. 2011;284(5):1163-8.

Simard C, Tu LM. Long-term efficacy of pelvic floor muscle rehabilitation for older women with urinary incontinence. J Obstet Gynaecol Can. 2010;32(12):1163-6.

Sousa JG, Ferreira VR, Oliveira RJ, Cestari CE. Avaliação da força muscular do assoalho pélvico em idosas com incontinência urinária. Fisioter Mov. 2011;24(1):39-46.

Burgio KL, Goode PS, Locher JL, Umlauf MG, Roth DL, Richter HE, et al. Behavioral training with and without biofeedback in the treatment of urge incontinence in older women: a randomized controlled trial. JAMA. 2002;288(18):2293-9.

Johnson TM 2nd, Burgio KL, Redden DT, Wright KC, Goode PS. Effects of behavioral and drug therapy on nocturia in older incontinent women. J Am Geriatr Soc. 2005;53(5):846-50.

Spruijt J, Vierhout M, Verstraeten R, Janssens J, Burger C. Vaginal electrical stimulation of the pelvic floor: a randomized feasibility study in urinary incontinent elderly women. Acta Obstet Gynecol Scand. 2003;82(11):1043-8.

Kim H, Suzuki T, Yoshida Y, Yoshida H. Effectiveness of multidimensional exercises for the treatment of stress urinary incontinence in elderly community-dwelling Japanese women: a randomized, controlled, crossover trial. J Am Geriatr Soc. 2007;55(12):1932-9.

Aslan E, Komurcu N, Beji NK, Yalcin O. Bladder training and Kegel exercises for women with urinary complaints living in a rest home. Gerontology. 2008;54(4):224-31.

Schreiner L, dos Santos TG, Knorst MR, da Silva Filho IG. Randomized trial of transcutaneous tibial nerve stimulation to treat urge urinary incontinence in older women. Int Urogynecol J. 2010;21(9):1065-70.

Sherburn M, Bird M, Carey M, Bø K, Galea MP. Incontinence improves in older women after intensive pelvic floor muscle training: an assessor-blinded randomized controlled trial. Neurourol Urodyn. 2011;30(3):317-24.

Wallis MC, Davies EA, Tahlib L, Griffiths S. Pelvic static magnetic stimulation to control urinary incontinence in older women: a randomized controlled trial. Clin Med Res. 2012;10(1):7-14.

Dumoulin C, Hay-Smith J. Pelvic floor muscle training versus no treatment, or inactive control treatments, for urinary incontinence in women. Cochrane Database Syst ver. 2010;(10):CD005654.

Amarenco G, Ismael SS, Even-Schneider A, Raibaut P, Demaille-Wlodyka S, Parratte B, et al. Urodynamic effect of acute transcutaneous posterior tibial nerve stimulation in overactive bladder. J Urol. 2003;169(6):2210-5.

Vandoninck V, van Balken MR, Finazzi Agró E, Petta F, Caltagirone C, Heesakkers JPFA, et al. Posterior tibial nerve stimulation in the treatment of urge incontinence. Neurourol Urodyn. 2003;22(1):17-23.

Olney RK, So YT, Goodin DS, Aminoff MJ. A comparison of magnetic and electrical stimulation of peripheral nerves. Muscle Nerve. 1990;13(10):957-63.

Bø K, Kvarstein B, Nygaard I. Lower urinary tract symptoms and pelvic floor muscle exercise adherence after 15 years. Obstet Gynecol. 2005;105(5 Pt 1):999-1005.

Alewijnse D, Mesters I, Metsemakers J, van den Borne B. Predictors of long-term adherence to pelvic floor muscle exercise therapy among women with urinary incontinence. Health Educ Res. 2003;18(5):511-24.

Offermans M, Du Moulin MF, Hamers JP, Dassen T, Halfens RJ. Prevalence of urinary incontinence and associated risk factors in nursing home residents: a systematic review. Neurourol Urodyn. 2009;28(4):288-94.

Coll-Planas L, Denkinger MD, Nikolaus T. Relationship of urinary incontinence and late-life disability: implications for clinical work and research in geriatrics. Z Gerontol Geriatr. 2008;41(4):283-90.

Durrant J, Snape J. Urinary incontinence in nursing homes for older people. Age Ageing. 2003;32(1):12-8. 